\title{
Knowledge Sharing as Communication via James W. Carey's Communication as Culture
}

\author{
Melanie D. Bacuño \\ Camarines Norte State College \\ mdbacuno@up.edu.ph
}

\section{Abstract}

Knowledge sharing in the academic setting can be conceptualized as a form of communication that has a potential for socio-cultural communication studies. This study argues that examining the discourse of James W. Carey on communication as culture, particularly his discussion on transmission and ritual views of communication, can deepen understanding of knowledge sharing among the research academics from a communication standpoint. Applying one of Herbert Blumer's assumptions on symbolic interactionism, this study further argues that the meaning of knowledge sharing as a form of communication among research academics could be found in the process by which the academics interact symbolically with others within and outside the academic community. The findings affirm through a phenomenological research design that knowledge sharing is communication. New perspectives in this communication phenomenon are examined through the ritual view of communication with interesting implications with the New Media Theory and with the symbolic interaction framework.

Keywords: James W. Carey's ritual view and transmission view of communication, symbolic interactionism, research academics, Philippines

\subsection{Introduction}

Organizations, local and abroad, that are knowledge-intensive face the challenge of putting up a knowledge management system in place to enhance its knowledge management processes. In the education sector, the flow of knowledge makes it possible to achieve the desired individual and organizational performance objectives, whether it is for instruction, research, extension, or even in administrative functions. Knowledge sharing is much more relevant in a higher education context, not only in the Philippines but also in other countries as well. The teachers or the faculty members are, practically speaking, knowledge workers themselves who deal every day with research knowledge like the development of a research idea, proposal, design, methodology, and result as a part of their core function. Particularly among state colleges and universities in the Philippines, when research productivity is high, the more beneficial it is for the institution and its members.

Using the lens of socio-cultural tradition of communication theory, the researcher postulated 
that knowledge sharing as communication can bring in social order in the society and within an organization. According to Craig (1999), communication in this tradition explains how microlevel interaction processes, such as knowledge sharing interactions between and among research academics create, realize, sustain, and transform social order as a macro-level phenomenon. Social order, in this study, is conceived as a state in which the education sector through the higher education institutions generate and provide knowledge to people and to different communities who will catalyze development in society, in general. The analysis focuses on interactions related to knowledge sharing among the academics, or the teaching personnel who have active involvement in research as the micro-level interaction processes. Rothenbuhler (1993, as cited in Craig, 1999) stated that when activities or artifacts have symbolic values that position an individual vis-à-vis each other or their collectivities, then communication is present. Hence, once the explanation unfolded on how the academics experience knowledge sharing based on observed actual research practices, further analysis of its symbolic "reality" can be explored. From this viewpoint, the researcher asserted that the academics as individuals are products of the academic community as a social environment, that groups such as the academics who actively engage in research develop particular practices and worldviews that can be meaningfully studied.

Previous socio-cultural studies on knowledge sharing such as that of Barachini (2009) argued that knowledge sharing is based on a trading process. She discussed this as an information exchange process such that people evaluate information on an individual basis in an asymmetric way. As to socio-cultural factors related to knowledge sharing, Barachini asserted on the cultural dependence of moral hazards for knowledge sharing among the Central European society that is based on existence needs, biological needs, and cognitive needs. This position appears similar to the present study by viewing knowledge sharing within a communication standpoint, but through the cybernetic lens, which views communication as information processing.

Okyere-Kwakye and Nor (2016), on the other hand, revealed in their research that some sociocultural factors like nepotism, tribalism, openness to diversity and cronyism affect an individual's knowledge sharing behavior of employees in a large global company located in India. Then, Annadatha (2012) found out that sociocultural factors like trust, shared language, and collaboration do not seem as important for knowledge sharing. Meanwhile, shared goals do seem to be an essential factor for knowledge sharing among knowledge workers in an information technology industry in the USA and India. It was also seen that faceto-face communications do not seem as crucial for building trust. Then, Bashir's (2014) study on societal, cultural considerations in knowledge sharing found out that from the United Kingdom culture, power distance, and uncertainty avoidance have a small negative relationship with knowledge sharing. In China, only power distance was revealed to have a negative relationship with knowledge sharing in a virtual community context. Moreover, on investigating a sociocultural perspective on knowledge transfer, Sarala, Junni, Cooper, and Tarba (2016) suggested that sociocultural interfirm linkages like complementary employee skills, trust, collective teaching, and cultural integration between merging firms influence the level of 
knowledge transfer. Evident from these empirical studies is the effect of the socio-cultural factors on knowledge sharing in organizations.

In 2013, Hubert and Lopez' paper on breaking the barriers to knowledge sharing discussed that developing an environment where people freely create, share, and use information and knowledge; working together toward a common purpose; and supporting and rewarding for doing so are roles of knowledge management. In the paper, the authors identified the corporate culture that does not embrace the value of knowledge sharing as one cultural barrier that impedes the flow of knowledge. The present study found support from Hubert and Lopez's when they magnified culture as a crucial factor in symbolically creating the "reality"of knowledge sharing as communication among the academics.

There is thin literature on knowledge sharing in academia with a focus on socio-cultural aspects studied through a qualitative approach of inquiry. More so is the observation that studying it within a communication perspective is limited. Research, being a core function of the academics, makes research knowledge, as a context-specific knowledge, an interesting area of study on knowledge sharing as a symbolic process that each member of the academia transforms to create, realize and sustain the very role of higher education in society. This phenomenon was thoroughly studied theoretically to unfold a meaningful "reality" of knowledge sharing as communication among research academics.

Carey (2008), in his paper, "A cultural approach to communication", offered a discussion on the conceptions of communication: the transmission view of communication and the ritual view of communication. The researcher referred to his explanations in unveiling the contextualized experiences of the academics in knowledge sharing as communication to arrive at a meaningful "reality". The span of application of the ritual theory of communication, while it is within the practice of theorizing new media, was probed in this study because of academics' attachments to media, both the traditional and the new media. The discourse was then extended by theoretically discussing this as a symbolic reality that is enacted in the interactions, hence the applicability of using the Symbolic Interaction (SI) Theory. Littlejohn and Foss (2009) discussed that the birth of symbolic interactionism happened when they applied their work to the study of social life by American sociologists Charles H. Cooley, W. I. Thomas, and George Herbert Mead. However, it was Mead who was given credit with systematizing this perspective. Although Mead died without having written a book on the subject, Herbert Blumer, one of his students, named the theory as symbolic interactionism. Symbolic Interactionism, as a theoretical view, assumes that people construct selves, social worlds, and societies through interaction. As a perspective, it offers a lens for looking at one's self such as the academics as an individual, our everyday life such as the academic life, and the world in which the education sector is part of a large society (Charmaz, Harris, \& Irvine, 2019). The examination of how the academics interpretations and definitions of knowledge sharing actions guide various aspects of life in the academe as social life was forwarded using one of Blumer's (1969) of symbolic interactionism.

Thus, this research, from the perspective of researchers in a Philippine higher education context, aims to explore the question what is it like to share knowledge? Because there were few 
studies exploring the experiences of research academics in knowledge sharing with a focus on socio-cultural aspects, a phenomenological study focused on describing research academics knowledge sharing experiences best lent itself to examining this question.

The study, in general sense, aims to reveal the meaningful "reality" of knowledge sharing as a communication phenomenon in the higher education setting, and then advanced to exploring the application of the New Media Theory and the symbolic interaction framework. The researcher noted, however, that the transmission view is a theory that assumes communication that occurs between two preexisting individuals. So it is through the discussion of the ritual theory that the assumptions of symbolic interactionism were found relevant. In particular, this assumption lies in the contention that selves and communities are created, reimagined, and recreated by and through communicative processes.

\subsection{Methodology}

Knowledge sharing is observed to be varied as diverse as the research academics and views of it varied depending on the individual facultyresearcher's experience and context. Given that the nature of reality of knowledge sharing is multiple and subjective, this qualitative research employed the phenomenological research design of inquiry to understand several individuals' common or shared experiences of knowledge sharing. Within the constructivist paradigm, the study assumed that the academics develop subjective meanings of their knowledge sharing experiences, which are varied and multiple but lead to a complex view of the phenomenon. Data gathered from a written interview using an open-ended question were analyzed into themes and interpreted to describe the essence of the knowledge sharing experience. In writing the discussion, observations regarding the existing knowledge sharing practices were integrated. Further, a theoretical investigation was done by providing an explanation using one of Herbert Blumer's assumptions of symbolic interactionism, that humans act toward others based on the meanings those others have for them.

Research academics, or faculty members, regardless of the field of discipline, who have active involvement in research activities in a public higher education institution in the Philippines, participated in this study. Generally, the participants were middle to senior age groups of academics actively engaged in research. They were employed with the institution for a relative time, but their academic rank is at entry-level, if not nearly above, which can be explained by the level of educational attainment.

Obtaining the qualitative data from the 39 participants was done in October 2018 by asking them to answer in written form an open-ended question on how they understand knowledge sharing as communication based on actual research practices. The responses were analyzed, wherein the responses were grouped; next, codes were derived; and then themes that emerged were discussed using James W. Carey's conceptualizations of communication. Boyatzis (1998) said that thematic analysis is a way of seeing; that is, how the researcher see the "reality" of knowledge sharing as communication among the academics may not appear to others even if they see the same information, events, or situations. Nevertheless, this enabled the use of a variety of information that increased understanding 
of the observations about the academics, their knowledge sharing activities, and the academic institution as an organization where the individuals interact with others in various situations.

\subsection{Results and Discussion}

A total of 43 codes were derived, wherein seven broad themes emerged, as shown in Table 1. From the interview statements, the emergent theme from the first group of codes established that knowledge sharing is an act of giving information and the representation of shared beliefs and shared experiences which suggests that for the research academics knowledge sharing as communication is more than just a process.
The next group of codes include quantitative and qualitative data, opportunities, discoveries, innovation, result, suggestion/feedback, thoughts and ideas. From here, the emergent theme is that the shared knowledge have different labels and forms. Like message as one of the elements of communication, knowledge being communicated as a message comes as an abstract concept like opportunity, innovation and the like or a concrete concept such as qualitative and quantitative data. The succeeding group of 16 codes indicate the different communication channels/methods/ strategies in sharing knowledge specifically reflecting that print, broadcast and the Internet have been used in interpersonal, group and mass communication levels.

Table 1. Codes and Themes for "Knowledge Sharing as Communication"

\begin{tabular}{|c|c|}
\hline Codes & Essential Themes \\
\hline $\begin{array}{l}\text { Dissemination and exchange of information, } \\
\text { knowledge, and skills among individuals and } \\
\text { within and among organizations and communities } \\
\text { Sharing of ideas, opportunities, discoveries, and } \\
\text { innovation } \\
\text { Two-way experience }\end{array}$ & $\begin{array}{l}\text { Knowledge sharing as } \\
\text { communication is an act of giving } \\
\text { information and the representation } \\
\text { of shared beliefs and shared } \\
\text { experiences. }\end{array}$ \\
\hline $\begin{array}{l}\text { Quantitative and qualitative data } \\
\text { Opportunities } \\
\text { Discoveries } \\
\text { Innovation } \\
\text { Research result } \\
\text { Suggestion/feedback, Thoughts, Ideas } \\
\end{array}$ & $\begin{array}{l}\text { Knowledge shared comes in various } \\
\text { forms and labels. }\end{array}$ \\
\hline $\begin{array}{l}\text { Blog, Social media, Radio and other mass media } \\
\text { Paper presentation, Journal publication, Book } \\
\text { publication } \\
\text { Conversations during break time and meeting } \\
\text { Research manuscript editing } \\
\text { Panel for research defense } \\
\text { Technical journal reviewing } \\
\text { Researcher, Research adviser/editor } \\
\text { Writeshop, Seminar, Training, Conference }\end{array}$ & $\begin{array}{l}\text { Knowledge sharing uses different } \\
\text { communication channels/methods/ } \\
\text { strategies. }\end{array}$ \\
\hline
\end{tabular}


Continuation of Table 1. Codes and Themes for "Knowledge Sharing as Communication"

\begin{tabular}{|c|c|}
\hline Codes & Essential Themes \\
\hline $\begin{array}{l}\text { Enhances one's knowledge level } \\
\text { Develops personality traits } \\
\text { Contributes to individual performance } \\
\text { Promotes collaboration } \\
\text { Builds a network/linkage } \\
\text { Management tool }\end{array}$ & $\begin{array}{l}\text { Individuals and groups share } \\
\text { knowledge for varied purposes. }\end{array}$ \\
\hline $\begin{array}{l}\text { Deepen organizational culture not only in research but } \\
\text { academically as well } \\
\text { Use as a management tool applicable to all } \\
\text { functional areas } \\
\text { Contribute to organizational performance }\end{array}$ & $\begin{array}{l}\text { Organizations benefit from } \\
\text { knowledge sharing. }\end{array}$ \\
\hline $\begin{array}{l}\text { Depends on one's skill and traits } \\
\text { Faculty aged } 50 \text { above not interested in research } \\
\text { knowledge } \\
\text { Culture of willingness to participate in research } \\
\text { activities challenging to attain } \\
\text { Cannot prevent duplication } \\
\text { Sharer has an ethical obligation } \\
\text { Creating a legacy }\end{array}$ & $\begin{array}{l}\text { Knowledge sharing is not free from } \\
\text { issues and challenges } \\
\text { Sub-themes } \\
\text { Researcher participation and } \\
\text { engagement } \\
\text { Ethical responsibility } \\
\text { A legacy }\end{array}$ \\
\hline Professorial chair & $\begin{array}{l}\text { Sharing knowledge entitles a person } \\
\text { to award/recognition. }\end{array}$ \\
\hline
\end{tabular}

The study also found out different reasons for knowledge sharing in the individual level. In this context, Faculty-Researcher \#5 said:

"Disseminating the results will create awareness and additional inputs to the participants, which may bring/give them opportunities for a new research idea, or they can utilize it in their respective jobs. It may also give birth to research collaboration with other institutions."

Then, Faculty-Researcher \#9 explained that sharing knowledge results in:

"broadening your horizon as to the research topic; it widens your network for future research collaborations; and it allows you to see a different perspective on the subject matter.

Furthermore, Faculty-Researcher \#35 asserted that sharing knowledge leads to a sustained interest in doing research and added,

"It creates span and inclusive dialogue on different options, deepens a research culture, and addresses stakeholders' expectations. It promotes transparency and accountability as well as establishes and maintains momentum."

Within an organization, Faculty-Researcher \#16 noted: 
"Knowledge sharing as communication is effective management - communication tool applicable to all functional areas in an organization like marketing, finance/ accounting, research/operation, management information system, etc."

Faculty-Researcher \#16 added:

"Knowledge sharing is an activity by which skills, information, or expertise are exchanged mutually among colleagues, friends or the organization to improve the individual"s and the organization's performance."

However, the academics are aware that issues and challenges related to demographics, other social and cultural factors can affect knowledge sharing. As Faculty-Researcher \#42 said:

"...most of our faculty aged above 50 are not interested in doing knowledge research and they don't like to participate in research proposals. The knowledge research is there, but the culture of willingness to participate in research activities is difficult to attain."

Finally, Faculty-Researcher \#30 noted that in knowledge sharing one can qualify to receive an award or recognition like a professorial chair.

In sum, knowledge sharing is communication that explains knowledge sharing per se as a phenomenon. It has components like the sender, the message, the recipient, etc. and is facilitated by various channels in order to achieve different purposes. Issues and challenges, which other authors call as interferences or barriers, are present but when a knowledge sharer overcome and excel in these can bring in to a person and to an organization the honor of an achievement.

\section{Discussion}

Carey's (2008) discourse on communication as culture has a fundamental role in the attempt to understand knowledge sharing as a communication phenomenon. This view about communication as culture, Carey noted, has existed in American culture since the 19th century, and his labeled descriptions are the "transmission view of communication" and the "ritual view of communication". Carey explained that the terms associated with the first view are: "imparting," "sending," "transmitting," or "giving information to others." Central to this notion of communication is the transmission of messages over distance for control. The goal here is to level up the "...speed and effect of messages...." On the other hand, the ritual view of communication is associated with terms such as "sharing", "participation","association", "fellowship", and "the possession of a common faith". It is directed "...toward the maintenance of society in time...", that is, sustaining order in the society, and "...the representation of shared beliefs..." which concerns depicting the statement of facts which can be real or not.

Analyzing from this discourse, it is manifested that the movement of knowledge, which actually comes as "qualitative" or "quantitative data", "opportunities", "discoveries", "innovation", "research result", and the like, from to another person, who may be the researcher him/herself and another researcher, an administrator, a faculty, a student, etc., is parallel with the transmission view of communication. Individuals or groups of 
academics that centrally produce the knowledge recognize that dissemination through knowledge sharing is an essential component of the research process. Passing on the benefits of research is strongly affirmed when they mainly see it as an "opportunity". Such a view is parallel with the goal of transmission view because, as researchers from a state-run higher education institution, they are expected to contribute to the generation of new knowledge that will improve the lives of the people and the society, in general.

In that sense, it is not surprising they use the media to good advantage for the transmission of knowledge the information and communication technologies (ICTs) like print and broadcast media such as books, journals, radio and television, as well as the new media, particularly "blog" and "social media". However, this does not exclude "conversations during break time", "workshop", "seminar", "training", and "conference" as well as "research manuscript editing" and "technical article reviewing" as means of imparting information that facilitate the movement of knowledge. The media, therefore, is instrumental for the increased speed and effect of the message.

A more in-depth inquiry based on this view could arise to questions linked to knowledge: as enlightening or obscuring reality mainly when a research result is judged as debatable; as changing or hardening attitudes about certain philosophical assumptions or ethical obligations; or as reflecting credibility or doubt about the researcher/ knowledge sharer. Such areas of interest, along with the transmission view when explored, can also contribute to the advancement of Carey's discourse in the current times' communicative processes.

Echoing Carey's ritual view of communication, the researcher noted that research academics also had this consequential belief that knowledge sharing can construct and maintain an "...ordered, meaningful cultural world..." Practically, this sustains the "being" of a higher education institution because of the faculty's commitment to work as an individual and with other members of the organization harmoniously. That surfaced from the statements where they acknowledge that knowledge sharing is "sharing" of ideas, which "promotes collaboration," and enables them to "build a network/linkage". It comes as no surprise because a recent study confirmed that research collaboration has a positive effect on "...new knowledge exploration..." and that "...a research collaboration strategy with the structure of a knowledge base is crucial for obtaining novel knowledge" (Xu, Li, \& Zhou, 2019). Another study revealed, "...international collaborations have a higher impact on the research quality..." (Aldieri, Guida, Kotsemir, \& Vinci, 2019), which is the goal of any academic research endeavor. The observation regarding the construction and maintenance of a social order goes on as the institution serves as "...a control and container for human action". Stemming from national research agenda, the institution designs and implements policies and programs, as well as provides the resources necessary for the academics to engage in research and research knowledge sharing.

Furthermore, from the lens of the ritual theory, knowledge sharing also portrays and confirms a particular view of the different factors related to "individual performance" and "organizational performance," "ethical responsibility," and "entitlement to award/ recognition" through a "professorial chair" which fosters emphasizing shared beliefs, exchanges 
and shared interactions among the researchers and other users of knowledge. The latter is critical because of its significance in developing and maintaining active communities, particularly among the knowledge workers themselves. From this, the society had projected the ideals that were created by the academic community and their representations in the material form are texts on research agenda, policies and programs, reports and accomplishments, academic activities like seminar and conference, academic journals and other publications, awards and incentives, and the like. Essentially, based on Carey's discourse, this creates a "...real symbolic order..." that confirms the "...underlying order of things and manifests... an ongoing and fragile social process." Grounded in the academics' definition, some of the factors that can affect this "ongoing and fragile social process" of knowledge sharing in the academe are changing social, political and economic conditions, ICT advancements, employees' job commitment and satisfaction, and the like.

In other words, when viewed through the ritual theory, one needs to point at wide-ranging problems associated with knowledge sharing. Moreover, it is in the role of material forms, as Carey asserted, like the texts on research agenda, policies, and programs, reports and accomplishments, academic activities like seminar and conference, academic journals and other publications, awards and incentives as"...a presentation of reality that gives life an overall form, order, and tone." Thus, questions encountered here and that can be further studied are: on the underlying meanings of a research direction set by an organization that shapes one's life as a researcher; on the nature of social bonds that are formed between and among the researchers themselves; and on the contextual background that explains academics' commitment to knowledge sharing.

Moreover, the study considered the symbolic construction of knowledge sharing within academia and on the broader public. Research academics define knowledge sharing as an act of imparting information and the representation of shared beliefs and experiences, consistent with the transmission view and ritual view of communication. Previous studies, however, show that communication is a predictor of knowledge sharing, and this merits a further analysis because the academics were giving more focus on maintaining social order by fulfilling their role as part of the higher education system than on simply disseminating knowledge.

Through the lens of symbolic interactionism, particularly Herbert Blumer's assumption that "... humans act toward others based on the meanings those others have for them," the study explored how the academia as an organization create and sustain a meaningful reality. West and Turner (2007) explained that the assumption is an explanation of behavior as associated conscious thought and behavior between stimuli and the responses that people show to those stimuli. In observing how the academics communicate or share knowledge in both formal settings such as through a meeting, conference, seminar, training, publication, etc. and informal setting like a conversation during break time to describe how the academics represented their organization, the researcher noted that an individual assigns meaning to one's knowledge sharing experience by applying commonly agreedupon interpretations to the things he/she sees.

When research academics share knowledge as a research journal author or a conference paper presenter, a faculty is likely to associate it to a sense 
of authority and to have credibility. Engaging in research and sharing his/her knowledge through different communication channels, methods, and strategies mainly through paper presentation and academic/scientific journal publication, the more contribution to the institution's research performance and outputs, which, in turn, establishes one's authority and credibility. In state universities and colleges (SUCs), involvement in research and knowledge sharing is a symbolic contribution in the research performance and outputs of a school, which is part of the criteria used by the Philippine Commission on Higher Education (CHED) in SUC leveling evaluation.

Equating it with the entitlement to an award or recognition in the form of professorial chair grants is another symbolic act. For example, the Southeast Asian Regional Center for Graduate Study and Research in Agriculture (SEARCA) awards a professorial chair to distinguished experts in the academe who have passionately advocated for agricultural and rural development initiatives in Southeast Asia (Southeast Asian Regional Center for Graduate Study and Research in Agriculture, 2019).In the University of the Philippines (UP), a professorial chair is a kind of award, with incentives, that recognizes faculty members who demonstrate outstanding performance in any two of the work areas of faculty in line with teaching, research or creative work, and public service (University of the Philippines, 2019).From this perspective, it can be noted the academics' awareness that knowledge sharing is symbolically associated with honor and recognition, reassuring that when one shares knowledge; he or she is entitled to it.

Academics' use of different communication methods, channels, and strategies affirm that their participation in knowledge sharing is essential and necessary. For instance, they acknowledge that sharing knowledge, whether oral or written, through print, broadcast and the new media, particularly the social media and blog, or in ways such as editing research manuscript, serving as panel for research presentation and a reviewer of a technical journal article results in enhancing one's knowledge level, developing personality traits, and generally, contributing to individual performance.

In ordinary situations, Charmaz, et al. (2019) explained that people attribute meanings as being inherent in an object, whether the object is a thing, a person, or event. Contrary to that is Blumer's premises, in general, which highlight the significance of meaning in the symbolic interactionist perspective, where it centers on the value of meaning associated with the academics' knowledge sharing. Concerning the observation that symbolic interactionists see human existence as fluid and in-process, the researcher concur with this thought because the meanings that are associated with knowledge sharing among academics can change and people's actions and interpretations can spur these changes.

In essence, research academics interact with other knowledge sharers and users based on meanings ascribed to knowledge sharing per se. The ascribed meaning of knowledge sharing comes from interactions with others and the academic community. The academics interpret the meanings of knowledge sharing relative to research productivity and output, which is an essential function among academics.

\subsection{Conclusion}

Examining knowledge sharing as a communication phenomenon that is a 
transmission and a ritual process in the academic setting is affirmed in this study. The research academics defined knowledge sharing as an act of imparting information and the representation of shared beliefs and experiences. Knowledge comes in different forms and labels such as qualitative and quantitative data, opportunities, discoveries, innovation, research results, and the like. Print, broadcast and the new media through social media and blog, then through journal and book publications, as well as conversations during break time and meeting, research manuscript editing, technical journal reviewing, workshop, seminar, training, and conference are the communication channels, methods, and strategies used in sharing knowledge. Individuals and groups share knowledge because it enhances one's knowledge level, develops personality traits, contributes to individual performance, promotes collaboration, and builds a network/linkage. Organizations benefit from knowledge sharing because it deepens organizational culture not only in research but academically as well; as a management tool, it applies to all functional areas; and generally, it contributes to organizational performance. Academics have an awareness of the issues and challenges linked to knowledge sharing such as those related to the level of participation and engagement, ethical responsibility, and on creating a legacy. Nevertheless, it entitles the knowledge sharer to an award or recognition such a professorial chair, which is an academic position created to recognize the significant contribution to scholarship and research of a faculty. It also gives them a sense of authority and credibility as an expert in a particular field of study.

The academic community has created the ideals of the society, which is being true to its purpose as a state-run higher education institution that contributes new knowledge to help understand and improve the lives of the people and the society. Different material forms represent such a view about the various elements of knowledge sharing as communication in the academic setting. The study, in a modest manner, has therefore contributed to expanding the application of the ritual view of communication, or the Ritual Theory situated under the New Media Theory, in knowledge sharing among the academics in higher education. Also, it offered for the communication scholars a new avenue where researches can be done, not only within the ritual view but also within the transmission view.

Furthermore, the findings have shown consistency with a symbolic interaction framework because of the communication processes and strategies employed by the research academics that symbolically construct knowledge sharing. These strategies and processes symbolically place the research academics as individual knowledge workers contributing to the role of the education sector in the society to sustain the academic institution.

\section{References}

Aldieri, L., Guida, G., Kotsemir, M., \& Vinci, C. P. (2019). An investigation of impact of research collaboration on academic performance in Italy. Quality \& Quantity, 53(4), 2003-2040.

Annadatha, J. V. (2012). Sociocultural factors and knowledge sharing behaviors in virtual project teams. Robert Morris University.

Barachini, F. (2009). Cultural and social issues for 
knowledge sharing. Journal of knowledge management, 13(1), 98-110.

Bashir, S. Usoro, A. and Khan, I. (2014). Knowledge sharing in virtual communities: A societal culture consideration. In International Conference on Knowledge Management.

Blumer, Herbert. (1969). Symbolic interactionism: Perspective and method. Berkeley.

Boyatzis, R. E. (1998). Transforming qualitative information: Thematic analysis and code development. Sage.

Carey, J. W. (2008). Communication as culture, revised edition: Essays on media and society. Routledge.

Charmaz, K., Harris, S. R., \& Irvine, L. (2019). The social self and everyday life: Understanding the world through symbolic interactionism. John Wiley \& Sons.

Craig, R. T. (1999). Communication theory as a field. Communication theory, 9(2),119-161.

Hubert, C. \& Lopez, B. (2013). Breaking the Barriers to Knowledge Sharing. American Productivity and Quality Center.

Littlejohn, S. W., \& Foss, K. A. (2009). Encyclopedia of communication theory (Vol. 1). Sage.

Okyere-Kwakye, E., \&Nor, K. M. (2016). The effect of socio-cultural diversity on knowledge sharing. Advances in Social Sciences Research Journal, 3(2),20-28.
Sarala, R. M., Junni, P., Cooper, C. L., \&Tarba, S. Y. (2016). A sociocultural perspective on knowledge transfer in mergers and acquisitions. Journal of Management, 42(5), 1230-1249.

Southeast Asian Regional Center for Graduate Study and Research in Agriculture. (2019). SEARCA Regional Professorial Chair Grants. Retrieved from https://www. searca.org/prof-chair-grants.

University of the Philippines. (2019). Call for Applications: One UP Professorial Chair and Faculty Grant Awards 2019-2021. Retrieved from https://www.up.edu.ph/index.php/ call-for-applications-one-up-professorialchair-and-faculty-grant-awards-2019-2021/

West, R., \& Turner, L. (2007). Communication theory. Analysis and Application. Singapore: McGraw Hill Companies.

Xu, L., Li, J., \& Zhou, X. (2019). Exploring new knowledge through research collaboration: the moderation of the global and local cohesion of knowledge networks. The Journal of Technology Transfer, 44(3), 822849. 